\title{
REDESCRIPTION OF PARAPAOLIA SUPERBA (SCUDDER) (PROTORTHOPTERA)
}

\author{
By F. M. CARPenter \\ Harvard University
}

In a general account of Palaeozoic insects, published in 1885, Scudder included keys to species of certain genera related to Dictyoneura (Palaeodictyoptera). One of the species mentioned under the genus Paolia was designated as new and named superba. The fossil was said by Scudder to have been collected at Mazon Creek, Illinois, by L. M. Umbach. Unfortunately, Scudder's description consisted of a single short sentence without the aid of a figure. What happened to the specimen after Scudder's examination of it is not clear; Handlirsch was unable to find it when he was preparing his revision of American Palaeozoic insects. At any rate, in 1918 it was in the possession of Dr. Umbach, who sold it at that time to the Field Museum of Natural History in Chicago. Through the courtesy of the authorities of the Museum I have been able to borrow the fossil and to prepare the following redescription and illustration. For reasons given below, I am placing the species in the family Palaeocixiidae of the Order Protorthoptera.

\section{Genus Parapaolia Handlirsch}

Parapaolia Handlirsch, 1906, Foss. Ins.: 121.

This genus was erected for superba without mention of generic characteristics. It differs from Palaeocixius, to which it seems to be related, by having the media forked at about mid-wing, instead of at the level of the origin of Rs.

Parapaolia superba (Scudder)

Figure 1

Paolia superba Scudder, 1885, Proc. Amer. Acad. Arts Sci., 20:173. Parapaolia superba Handlirsch, 1906, Foss. Ins. : 121 .

Fore wing, length, $90 \mathrm{~mm}$; width, $23 \mathrm{~mm}$. Sc terminating 108 
well beyond mid-wing. $\mathrm{R}_{\mathrm{s}}$ arising in the proximal quarter of the wing, and having its first branch arising just beyond mid-wing. $\mathrm{CuA}$ apparently free from $\mathrm{M}$; anal veins unknown. Sc and $R_{s}$ are distinctly concave in the obverse half of the fossil, and $R$ is equally convex. $M$ and its branches appear slightly concave, as is the case in most Protorthoptera.

The hind wing is very incompletely known; it apparently has a more rounded apex than the fore wing, and the radial sector arises nearer the middle of the wing, but the branching of $\mathrm{Rs}_{\mathrm{s}}$ and $\mathrm{M}$ is apparently like that of the fore wing.
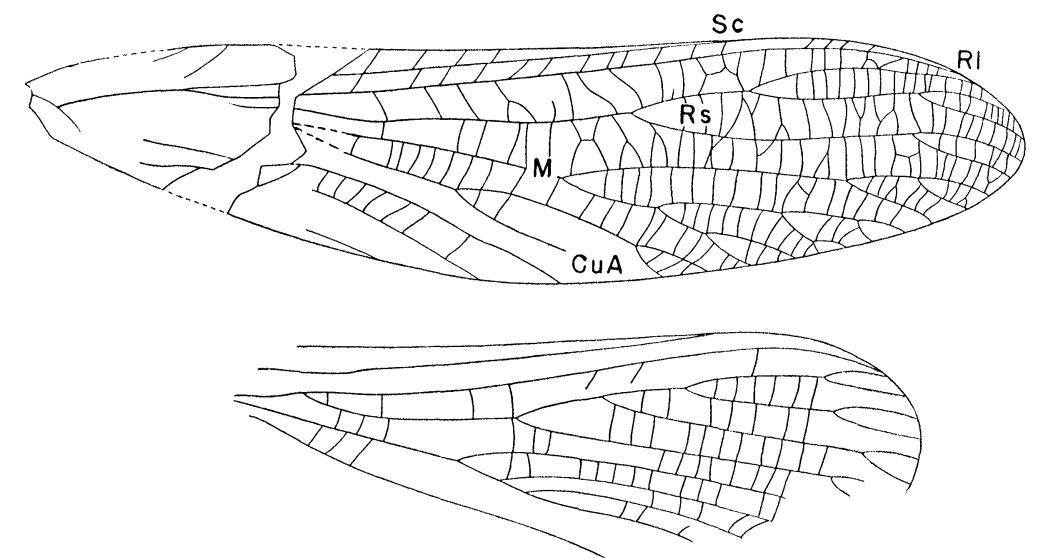

Figure 1. Parapaolia superba (Scudder). Fore and hind wings, drawn from holotype.

Holotype: Chicago Museum of Natural History; collected at Naperville, DuPage Co., Illinois, by Dr. L. M. Umbach. The fossil consists of two wings, with parts of the other two, superimposed and resting over the abdomen, no part of which can be distinctly seen.

Scudder placed this specimen in the Palaeodictyoptera, 
but since he arbitrarily assigned all Palaeozoic insects to that order, his system of classification is without phylogenetic significance. Handlirsch, who, of course, had no real knowledge of the species, placed it in incertae sedis under the Palaeodictyoptera. I have removed the species from that order for two reasons: 1) the superimposed wings strongly indicate that the insect was neopterous; and 2) there is no convex anterior media, the division of the media being remote from the origin of $M$. The insect therefore seems most probably protorthopterous, though its family affiliation is not clear because of the poor preservation of the wing. I have provisionally placed it in the family Palaeocixiidae, since it shows some resemblance to Palaeocixius.

Adlerzia Froggatti Forel and Some New Synonymy (HYMENOPTERA: FORMICIDAE) - In another paper, now in press, I have discussed the confusion attendant on Forel's description of Adlerzia, based on a stray worker of a single species and wrongly placed as a subgenus of Monomorium. It has since been determined that two subsequently described ants placed in different genera represent different castes of $A$. froggatii. The following synonymy is suggested here in order to avert proposal of a new name for s.tenothorax McAreavey, which is preoccupied by Harris and by Agassiz:

\section{Adlerzia froggatti Forel}

Monomorium (Adlerzia) froggatti Forel, 1902, Rev. Suisse Zool., 10:445-447, worker [minor] ; original description.

Machomyrma silvestrii Emery, 1914, Boll. Lab. Zool. Portici, 8: 182, fig. 2, soldier; new synony my.

Stenothorax katerinae McAreavey, 1949, Proc. Linn. Soc. N. S. Wales, 74:3-4, figs. 7-16, worker major [ergatoid?]; worker minor; new synonymy.

Stenothorax McAreavey, nec Harris, nec Agassiz, with the genotype and sole species katerinae (loc. cit.) becomes an absolute synonym of Adlerzia Forel by isogenotypy; new synonymy. - BY William L. Brown, JR., Museum of Comparative Zoology. 

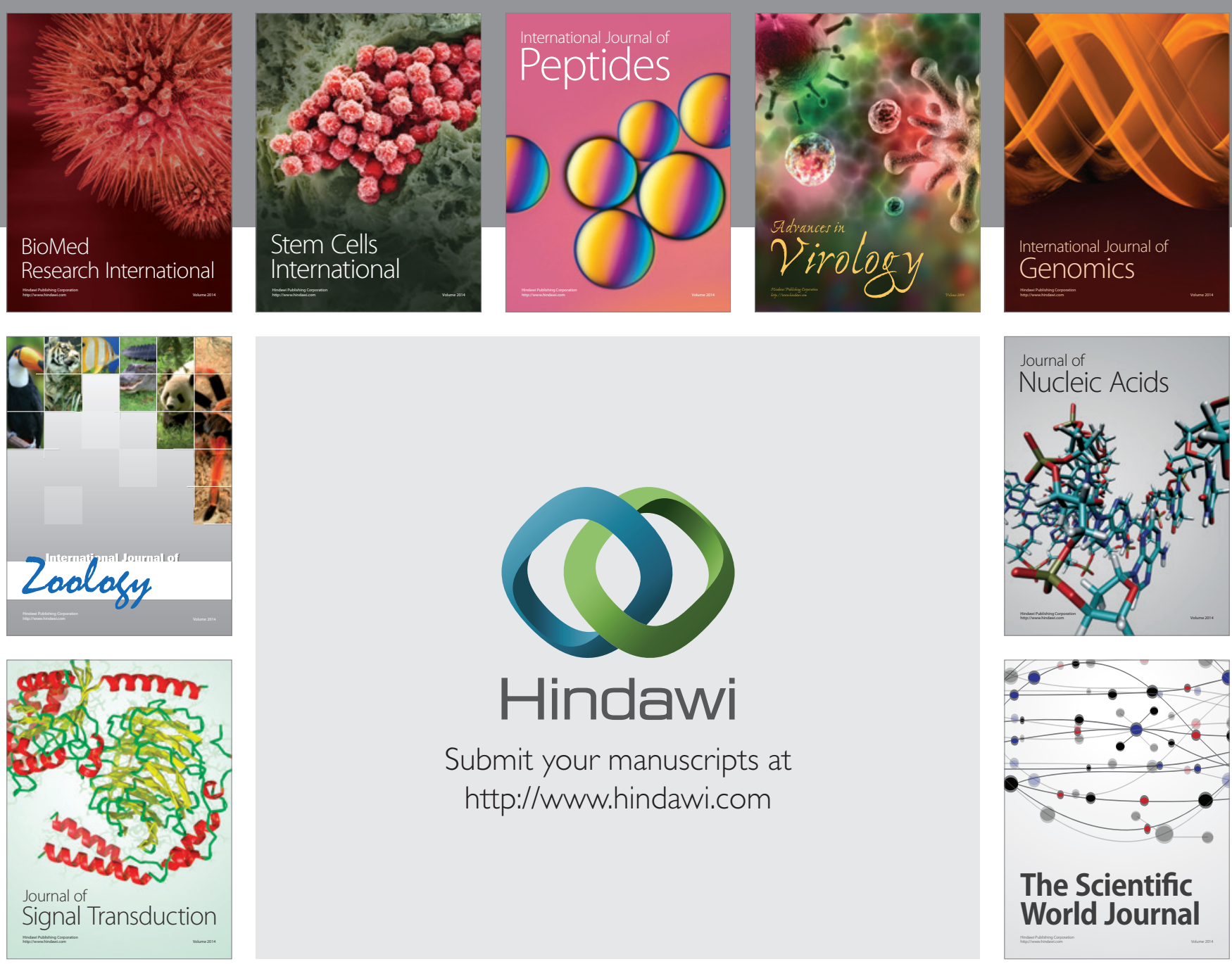

Submit your manuscripts at

http://www.hindawi.com
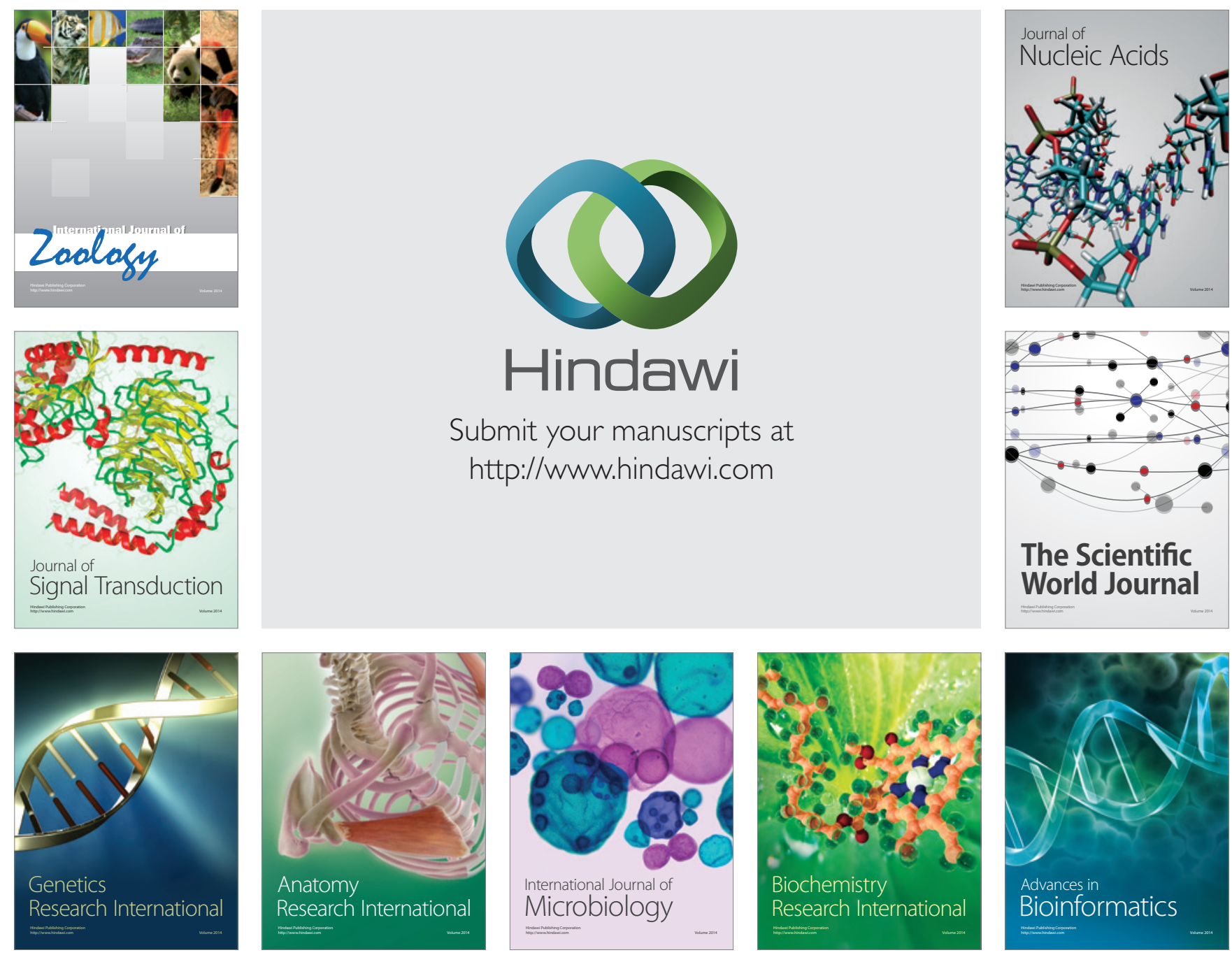

The Scientific World Journal
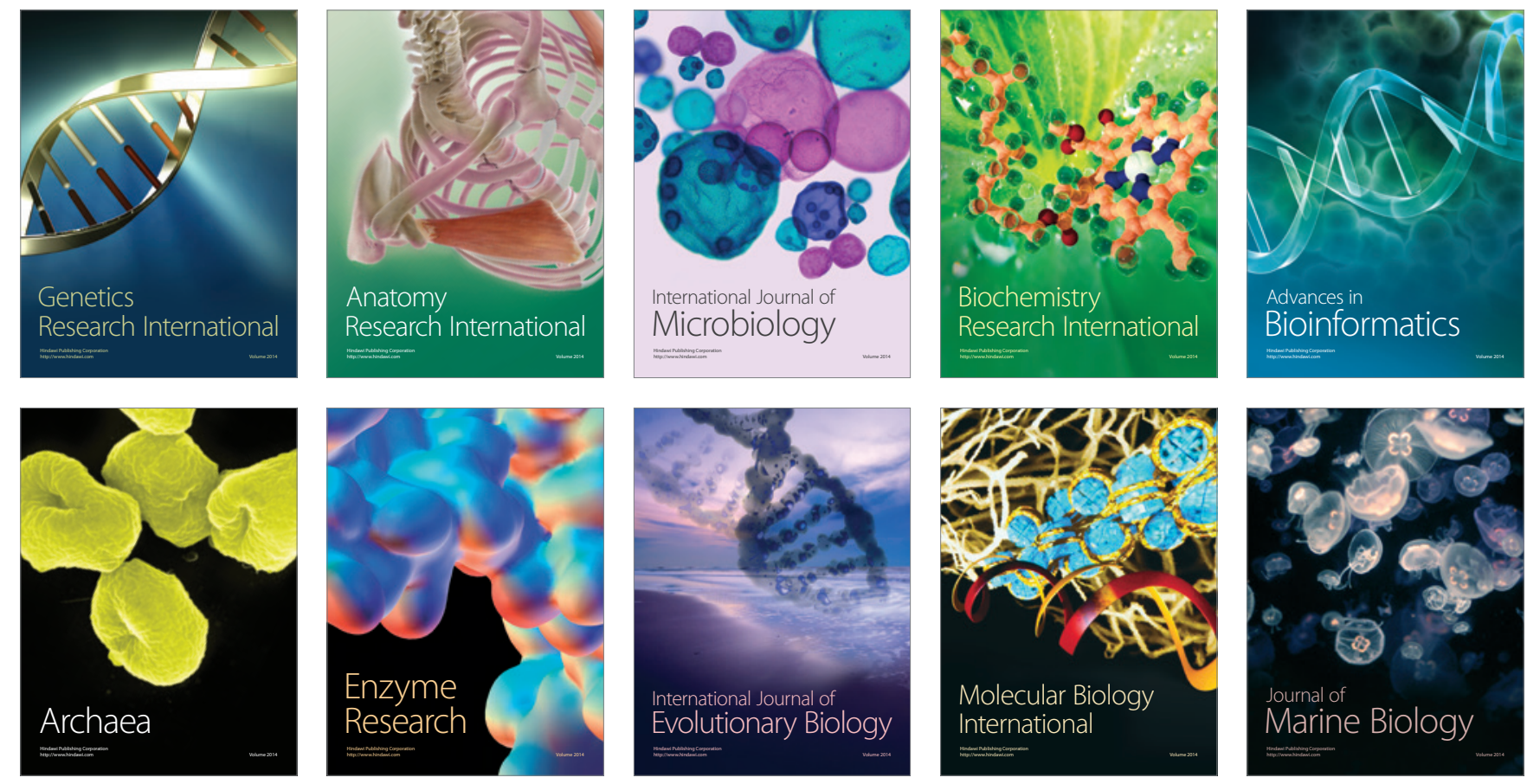